\title{
Battle between mitigation and adaptation: the future challenge of climate change
}

\author{
Climate change is caused not only by higher greenhouse gas (GHG) concentrations, \\ but a variety of natural and anthropogenic driving forces affecting the global energy \\ balance, including e.g., land use changes and aerosol emissions. Climate change po- \\ licy requires both mitigation activities designed to reduce GHG emissions, and adap- \\ tation policies addressing changes to natural eco- and climatic- systems caused by \\ climate change.
}

EEVA KUNTSI-REUNANEN

Finnish Meteorological Institute

Climate change is linked to virtually all aspects of modern economics: electricity consumption, heating and cooling of buildings, transportation, agriculture, forestry, waste management, use of chemicals, industrial production processes, etc. Climate change, moreover, impacts biodiversity systems, contributes to water scarcity problems, and sea level rise. Climate change is thus, very much a core sustainability issue (VijayaVenkataRaman et al. 2012; IPCC 2013).

There are basically three options for the reduction of $\mathrm{CO} 2$ emissions; (i) reduction of carbon intensive energy use, (ii) switch to less carbon intensive fuels or (iii) efficiency improvement of the energy system (Kuntsi-Reunanen 2007). The efficiency improvement is related to (i) the socio-cultural development of the society, (ii) economic and structural development and (iii) technological development (Sun and Kuntsi 2004). Within the economic development, it is essential how the role of industrial development and its structure in the globalised economy (e.g. shift of heavy and polluting industry to developing countries) relates to the development of other sectors (e.g. service sector and tourism) (Sun and Kuntsi 2004; Kuntsi-Reunanen 2007). The mitigation also involves reducing the flow of heat-trapping GHGs into the atmosphere by enhancing the "sinks" that accumulate and store these gases (such as the oceans, forests and soil). Moreover future solution for cutting $\mathrm{CO} 2$ emissions might be the nature based solutions (NBS) as they help to remove emissions from the atmosphere. Negative emission technologies (NET) are likely to be needed in order to stabilize global warming at 1,5 ${ }^{\circ} \mathrm{C}$, the target to which governments committed to, in the Paris Agreement (IPCC 2018).

Even if emissions of GHGs are reduced radically, climate will continue to change, at least for the foreseeable future. This is because the interdependent physical, chemical and biological processes in the oceans, atmosphere and on land do not respond instantly to changes in GHGs as they have mean residence times in the atmosphere from decades to over a century. While it is essential that humans reduce their distracting impact on climate and ecosystems, they should act immediately to begin to prepare themselves for local to global climatic changes they have been contributing to since the industrial revolution (Ruth 2010).

Adaptation requires adjustment to the actual or expected future climate. The aim is to reduce our vulnerability to the harmful effects of climate change (such as sea level intrusion, stronger extreme weather events or food insecurity). It also includes exploiting any beneficial potential opportunities associated with climate change (e.g. longer periods of growth or increased yields growth in some regions).

Although climate change is a global issue, it is felt locally. Cities and municipalities are therefore at the frontline of adaptation. In the absence of national or international climate policy direction, cities and local communities around the world have been focusing on solving their own climate change-related problems. They are working to build flood defences, plan for heatwaves and higher temperatures, install water-permeable sidewalks to better deal with floods and rainwater and improve water storage and use (Gandini A. et al. 2021).

However, governments at different levels are becoming better at adaptation. Climate change is starting to be taken into account in various development plans: how to manage the increasingly extreme disasters and associated risks, how to protect coastlines and deal with sea-level encroachment, how to best manage land and forests, how to deal with and plan for reduced water availability, how to develop sustainable crop varieties and how to protect energy and public infrastructure etc. 
In terms of climate change policy, mitigation continues to receive more attention than adaptation. This can be explained by a number of reasons, such as the urgency of emission reductions, the lack of time of adaptation, the risk and complexity of analysis and methods used in adaptation, and the lack of information on adaptation itself and the measures used in adaptation.

The balance between mitigation and adaptation about climate change is challenging for various reasons. Climate change is characterised by large uncertainties, time lags, and large differences in costs and benefits around the world. Furthermore, climate change impacts a number of properties that are difficult to value, including ecosystems, biodiversity, and quality of life, and it has not been possible to establish meaningful and reliable economic estimates of climate change damages. The estimated benefits of substantially reducing GHGs are diffuse across the globe, uncertain or unknown in terms of probability and magnitude, and primarily fall far in the future (Kuntsi-Reunanen 2015).

According to Tubi et al. (2012), the failure of international mitigation efforts so far, despite the widespread attention they gained, indicates that climate change is a politically difficult problem to address. Furthermore, it is a global problem, whose solution cannot be achieved through the efforts of any single state or small group of states. In addition, the negative effects of climate change are largely long term, and there- fore are not readily perceptible at present. Hence, mitigation policies imply that present generations pay for the benefit of future generations. Mitigation requires large-scale behavioural changes, but in many cases, governments lack the incentive or ability to bring them about. Thus, while collective action is needed to tackle climate change, all countries have a dis-incentive to undertake such action as they currently enjoy advantages from the activities that contribute to global warming, but believe they will suffer only a fraction of the environmental costs in the future (Anderson and Bows 2011; Rosen and Guenther 2015).

The world has changed remarkably since the climate convention was signed in 1992. Several countries have developed massively since then. Many industrial countries are now more aware of the risks, as well as the difficulties, impacts, and opportunities associated with climate change. Many developing countries have developed economically and some of them have already achieved the level of industrialized countries. At the same time, the direct effects of climate change have become commonplace and have caused serious damages in some vulnerable developing countries. There is an urgent need for adaptation measures (Kuntsi-Reunanen 2015).

It should be noted that substantial changes in population size, age structure, and urbanization are expected in many parts of the world this century. Statistical analysis of historical data suggests that population growth has been one driver of emissions growth over the past several decades and that urbanization and aging can also affect energy use and emissions. As the living standard rises and population continues to grow, energy use and $\mathrm{CO} 2$ emissions in city areas do the same. Aging can reduce emissions in the long term by up to $20 \%$, particularly in industrialized country regions. In contrast, urbanization can lead to an increase in projected emissions by more than $25 \%$, especially in developing country regions (O'Neill et al. 2010).

The pursuit of a carbon-neutral world in 2050 sounds promising but ambitious. Mitigation can have significant local benefits when generating outcomes that make good sense irrespective of climate change. Conversely, local adaptation can have national and global benefits when it frees up productive resources instead of drawing them into disaster mitigation. Furthermore, considerable overlap between climate change mitigation and adaptation actions exists, and spending on one can simultaneously advance the goals of the other (Ruth 2010). Instead of battle between mitigation and adaptation, these two should work hand in hand for a common goal.

Acknowledgements: This paper was supported by the Climate change adaptation: regional aspects and policy instruments (SUOMI) project funded by the Ministry of Environment of Finland and Academy of Finland Flagship ACCC (grant number 337552).

Anderson, K. and Bows, A., 2011: Beyond 'dangerous' climate change: emission scenarios for a new world, Philosophical Transactions of the Royal Society, 369, 20-44.

Gandini, A. et al., 2021: Climate change risk assessment: A holistic multi-stakeholder methodology for the sustainable development of cities, Sustainable Cities and Society, 65, https://doi.org/10.1016/j.scs.2020.102641.

IPCC, 2013: Climate change 2013: The physical science basis. Contribution of working group I to the Fifth Assessment Report of the IPCCC. Edited by Stocker, T.F., et al., Cambridge University Press.

IPCC, 2018: Global Warming of $1.5^{\circ} \mathrm{C}$.An IPCC Special Report on the impacts of global warming of $1.5^{\circ} \mathrm{C}$ above pre-industrial levels and related global greenhouse gas emission pathways, in the context of strengthening the global response to the threat of climate change, sustainable development, and efforts to eradicate poverty [Masson-Delmotte, V., P., et al.]. In Press

Kuntsi-Reunanen, E., 2007: A comparison of Latin American energy-related CO2 emissions from 1970 to 2001 , Energy Policy, 35, 586-596.

Kuntsi-Reunanen, E., 2015: Climate change and global responsibility - the role of energy consumption, GDP and CO2 emissions, Annales Universitatis Turkuensis, All, 308.

O'Neill, B. C., et al., 2010: Global demographic trends and future carbon emissions, PNAS, 107(41), 17521-17526, https://doi.org/10.1073/ pnas.1004581107.

Rosen, R. A., and Guenther, E., 2015: The economics of mitigationg climate change: What can we know?, Technological Forecasting \& Social Change, 91, 93-106.

Ruth, M., 2010: Economic and social benefits of climate information: Assessing the cost of inaction, Procedia Environmental Sciences, 1, 387-394. Sun, J. W., and Kuntsi, E., 2004: Environmental impact of energy use in Bangladesh, India, Pakistan and Thailand, G/obal Environmental Change, 14, 161-169. Tubi, A., et al., 2012: The effect of vulnerability on climate change mitigation policies, Global Environmental Change, 22, 471-482.

VijayaVenkataRaman, S., et al., 2012: A review of climate change, mitigation and adaptation, Renewable and Sustainable Energy Reviews, $\mathbf{1 6}(1), 878-897$. 